\title{
Organisation of services for managing ADHD
}

\author{
D. R. Coghill ${ }^{1,2,3}$ \\ ${ }^{1}$ Departments of Paediatrics and Psychiatry, University of Melbourne, Parkville 3052, Victoria, Australia \\ ${ }^{2}$ Murdoch Childrens Research Institute, Flemmington Road, Parkville 3052, Victoria, Australia \\ ${ }^{3}$ Integrated Mental Health, Royal Children's Hospital Melbourne, Parkville 3052, Victoria, Australia
}

There is considerable variation in practice, both between and with different countries in the management of attention deficit hyperactivity disorder (ADHD). Whilst there is no one optimal model of service organisation there are general principles of care that can be introduced to reduce this variability. There are frequent debates and discussions about which professional group is best placed to manage ADHD at different points in the life cycle. Who delivers care is however less important than ensuring that training schemes provide adequate exposure, training and experience to both the core and non-core skills required to provide a comprehensive package of care. Most evidence-based guidelines recommend a multi-modal, multi-professional and multi-agency approach. Many also promote the use of both stepped care and shared care approaches for the management of ADHD. As most of those with ADHD continue to have ADHDrelated problems into adulthood, it is important to consider how best to transition care into adulthood and think about who should deliver care to adults with ADHD. Young people with ADHD should generally be transferred to adult mental health services if they continue to have significant symptoms of ADHD or other coexisting conditions that require treatment. Unfortunately services for adults with ADHD remain relatively scarce across much of the world and some adult psychiatrists remain unsure of the diagnosis and uncertain about the appropriate use of ADHD medications in adults, but there is a strong case for increased services for adults. ADHD is on the one hand easy to treat; it is much more difficult to treat well. Although optimised care for ADHD requires routine measurement of outcomes, this often does not happen in routine clinical practice. Focusing on optimising symptoms and minimising adverse effects can significantly improve both short- and long-term outcomes.

Received 3 November 2016; Accepted 6 November 2016; First published online 22 December 2016

Key words: ADHD, medication, outcomes, treatment.

Attention deficit hyperactivity disorder (ADHD) is a common neurodevelopmental disorder, which is associated with significant impacts on functioning and quality of life (Danckaerts et al. 2010; Coghill \& Hodgkins, 2016) and is frequently associated with a broad range of coexisting or comorbid disorders (MTA Cooperative Group, 1999). Despite the fact that evidence strongly suggests that ADHD is equally common across the globe with a prevalence of about 5\% (Polanczyk et al. 2007), there are striking differences in the rate of diagnosis in different regions (Hinshaw et al. 2011). Rates of diagnosis in the USA, for example, are far in excess of the epidemiological prevalence (e.g. Visser et al. 2014). In Europe and many other Westernised countries, whilst the rates of diagnosis and treatment have risen considerably over the past 15 years they remain, much lower than the USA (Huss et al. 2008; Holden et al. 2013; Australian Commission on Safety and Quality in Health Care,

Address for correspondence: D. R. Coghill, Departments of Paediatrics and Psychiatry, University of Melbourne, Parkville 3052, Victoria, Australia.

(Email: david.coghill@unimelb.edu.au)
2015) (although see Geirs et al. 2014). In other continents, including much of Asia, Africa and South America rates of recognition remain very low (Hinshaw et al. 2011). Not only is there considerable variation between different regions and countries, but similar variability in practice is also seen within countries (Rowlingson et al. 2013; Visser et al. 2013, 2014; Australian Commission on Safety and Quality in Health Care, 2015). Attempts to explain the source of these within country variations in care have been largely unsuccessful (Wright et al. 2015).

Another source of complexity facing those wishing to design and deliver services for ADHD relates to the developmental trajectory. It is now clear that ADHD frequently persists over time and that, whilst many of those with ADHD in childhood do not meet full diagnostic criteria as adults, the majority, about two-thirds, will continue to have significant ADHDrelated disability (Faraone et al. 2006). However, there has also been a suggestion from several recent studies that a significant proportion of those with ADHD in adulthood did not present as having ADHD in childhood (Moffitt et al. 2015; Agnew-Blais et al. 2016; Caye et al. 2016). Whilst this remains a 
somewhat controversial proposition (Faraone \& Biederman, 2016) it does if true it adds yet another layer of complexity to the picture. It is also the case that different life stages are associated with very different patterns of comorbidity, associated features and impairment.

All of these issues contribute to the complexity of designing and organising services to manage ADHD. On top of this there is of course the practical reality that there are many different approaches to delivering healthcare across the world. Some countries rely almost completely on privately delivered healthcare services, whilst in others services are almost all publically funded. Whilst many have a mixed private/public approach, there are wide variations in the balance between these two approaches. There are also considerable differences in the wat doctors are trained. In Italy and Spain, for example, child and adolescent psychiatry is not seen as a separate specialty. As a consequence it goes without saying that there is no one optimal model of service organisation and delivery that will fit all systems of care. This does not however mean that we should not look for general principles of care that can be generalised and adapted to these different contexts. For the rest of this editorial we explore some of these.

\section{Who should be responsible for delivering the care for those with ADHD?}

Some of the questions that are frequently asked include: should ADHD be managed in primary or secondary care; in children and adolescents should it primarily be the responsibility of paediatricians or child and adolescent psychiatry; who should take over in adulthood; what are the roles of non-medical professions. There is little in the way of empirical evidence to answer these questions and in each situation the best answer will usually depend on a combination of who is available, what skills, experience and training they have, what type of patients are being referred and regrettably but importantly what the funders will pay for. In countries where ADHD is still under recognised, under diagnosed and under treated it seems likely that most of those referred for treatment will be at the more severe end of the ADHD spectrum, present with high levels of comorbidity and a have a wide range of impairments that impact significantly on all aspects of their lives. In this situation, I believe that there are strong reasons to suggest that care should be coordinated and to a large degree delivered within more specialist secondary care settings by child and adolescent psychiatrists or paediatricians with training not only in diagnosing and treating ADHD, but also in the assessment and management of the common comorbid conditions. Whether a paediatrician or a psychiatrist takes the lead in delivering care for ADHD for children and adolescents matters less than ensuring that training schemes provide adequate exposure, training and experience to both the core and non-core skills required to provide a comprehensive package of care for these patients.

Usually the more complex cases will be best managed by a multi-disciplinary team that could include psychologists, occupational therapists, social workers and specialist nurses. It is also helpful to have access to other allied health professionals such as speech and language and some services have been able to demonstrate the benefits of having teachers embedded within the clinical team. The aim is to bring together a broad set of skills that allow the team to manage not only the core features of ADHD, but also the common comorbid conditions and make sure that the broader impairments are properly case managed. From my own experience I have often said that the most important addition to my clinical team was a family therapist. Family therapy has not been shown to be an effective treatment for ADHD per se but with access to skilled family therapy many families affected by ADHD can make better use of other evidence-based treatments. This multi-modal, multi-professional and multiagency approach is endorsed by many of the evidencebased guidelines (e.g. NICE, 2008). It is tempting to think that, in those situations where less complex cases of ADHD are referred; then it may be more appropriate for primary care professionals to be involved in diagnosing and managing these cases. Whilst it is certainly true that most general paediatricians and general practitioners should be able to assess and manage less complex cases very well it is also possible that there is an increased risk that assessments will be less comprehensive and that as a consequence diagnosis may be less accurate and important comorbidities missed. This can be a consequence of a less comprehensive training but also simply related to the amount of time available to conduct the assessment. Key components of a full assessment process include a clinical interview, a medical examination and gathering information from multiple sources such as teachers. Other components such as direct observation in educational settings, cognitive, neuropsychological, developmental and literacy skills assessments are often but not always indicated. Most of the major ADHD guidelines recommend that the assessment of ADHD will require more than one visit (Taylor et al. 2004; NICE, 2008). This is often technically very difficult within primary care where time is often constrained. Specific approaches to management are discussed in more detail below but it is clear that in order to provide an integrated approach to treatment that includes pharmacological, non-pharmacological 
and more general case management approaches a multi-disciplinary approach is again required. Whilst this need not be delivered by an integrated multidisciplinary team located within a single service or agency the goal should be for the coordinating clinician or case manager to ensure that they and their patients can access the full range of assessments and treatments required to manage their ADHD, associated impairments and comorbid conditions. In some circumstances, this will simply mean accessing the multi-disciplinary team whilst in others it will require a more creative approach and a degree of lateral thinking.

NICE (2008) and other authorities have supported the development of structured stepped pathways for the management of ADHD in children, adolescents and adults. Stepped care traditionally reflects approaches to managing and utilising the primary-secondary care interface for chronic conditions. In these models, children and families move up or down a step in the care pathway depending on their particular needs and outcomes at the time as well as what has worked and not worked in the past. The precise configuration and triggers for moving up and down through the tires will be dependent on local services. Whilst this would appear to be a very attractive model there are unfortunately currently very few data evaluating the various models. Alongside the stepped care approach it is often important to consider a shared care approach. The most typical shared care will be for the specialist team to monitor care and make adjustments to treatment depending on response, adverse effects and any comorbid problems and for the primary care team to prescribe medication and, sometimes, monitor growth and blood pressure as required in between the specialist appointments.

\section{Managing transition and care for adults with ADHD}

As most of those with ADHD in childhood continue to have ADHD-related problems into adulthood, it is important to consider how best to transition care into adulthood and think about who should deliver care to adults with ADHD. NICE (2008) has recommended that young people with ADHD should generally be transferred to adult mental health services if they continue to have significant symptoms of ADHD or other coexisting conditions that require treatment. The precise timing of transition will vary depending on local circumstances, but most authorities agree that transfer should usually be completed by the time the patient is 18 years of age. Whilst these appear to be sensible guidelines implementation seems to be more complex. Evidence from the UK suggests teenagers start to disengage from treatment starts early in their teens well before clinical teams are considering transition
(McCarthy et al. 2009). Both NICE and the UK Adult ADHD Network has suggested that planning for transition should commence well in advance and should involve both the referring and receiving services (NICE, 2008; Young et al. 2016). It is also important to consider the potential barriers to successful transition. The most pressing problem is usually a lack of access to specialty care and support services at crucial stages of need but there are other factors that frequently contribute these include: both patients and caregivers not anticipating the changing treatment needs when transitioning to adulthood and a reluctance on the part of some paediatricians to refer their patients, who have seen themselves as paediatric patients to mental health services. Loss of healthcare coverage under parent's health insurance and the loss of access to ADHD medications approved in childhood but not adulthood are also common problems (Kooij et al. 2010; Goodman et al. 2011; Turgay et al. 2012).

As noted above services for adults with ADHD remain relatively scarce in many countries. Some adult psychiatrists remain unsure of the diagnosis and uncertain about the appropriate use of ADHD medications in adults. Some continue to voice concerns about treating a 'non-existent disorder' and the risks of causing drug addiction with stimulant medication, despite strong evidence to the contrary (Stockl et al. 2003). Stigma about ADHD is still common and almost always arises in the context of lack of awareness or understanding of available information. However, even those adult psychiatrists who do accept ADHD in adults as a valid and impairing disorder often argue that it falls outside their remit, which has increasingly become defined as 'severe and enduring mental illness' which typically means schizophrenia, bipolar disorder and severe depression. NICE (2008) have made a strong case supporting the need for services for adults as have other groups and organisations (Kooij et al. 2010; Bolea-Alamanac et al. 2014). It is to be hoped that these recommendations will find broader take up and implementation in coming years.

\section{Managing the treatment of ADHD: a condition that is easy to treat but not easy to treat well}

Systematic reviews and clinical guidelines agree that there is considerable evidence to support the efficacy and, to a lesser degree, effectiveness of ADHD treatments (e.g. Banaschewski et al. 2006; AAP Subcommittee on Attention-Deficit/Hyperactivity et al. 2011; BoleaAlamanac et al. 2014) although evidence for pharmacological treatments is somewhat stronger than that for nonpharmacological approaches (Sonuga-Barke et al. 2013). However, evidence for implementation of the available 
guidelines is generally not great (Leslie et al. 2004; Langberg et al. 2009; Gordon et al. 2016) and highly variable (NHS Quality Improvement Scotland, 2008). Also the quality of outcome of cases treated under regular community settings reported in the literature is disappointing (Langley et al. 2010; Setyawan et al. 2013) and it appears to be difficult to maintain the positive impacts of clinical trials beyond the end of the study intervention (Molina et al. 2009). Whilst some have suggested that this may indicate that ADHD medications are not effective in the long term there are clearly alternative explanations (Banaschewski et al. 2009). Perhaps the two most likely are that when patients self-select treatments they do not always choose the most effective or that optimal effects of treatment are dependent on the quality of care given. Coghill and Seth (2015) provided some support for the second of these suggestions when they demonstrated significantly improved outcomes following a careful titration onto medication and that, with careful monitoring using a standardised protocol, the mean treatment response for many patients with regards their ADHD symptoms remained strong for up to 10 years post-titration. This emphasises the potential benefits of using standardised approaches to closely monitor symptom outcomes over time. More work is needed however to demonstrate whether this approach can be translated across the various healthcare systems described earlier in this piece.

It is also clear that treating the core symptoms of ADHD is only one aspects of a comprehensive approach to care and that clinical systems need to adopt a holistic approach to case management. Thus, we have argued elsewhere that clinicians need to consider a broad range of clinical outcomes. These include cognitive, functional and quality of life outcomes each one of which taps into a different aspect of ADHD (Adamo et al. 2015). Recent evidence has challenged the notion that cognitive and symptom outcomes for ADHD are inextricably entwined (Coghill et al. 2013). These data, and others, suggest that, whilst those with ADHD often have impairing cognitive deficits, these are not always directly associated with the core symptoms. The implications of this are important. It means, for example, that treating the core symptoms successfully may not lead to a similar improvement in cognition (e.g. working memory, planning, etc.) and vice versa. It may therefore be necessary to independently treat both problems in order to reduce impairment. The ultimate aim of treating ADHD is to reduce impairment and improve quality of life (Danckaerts et al. 2010) and whilst it is very clear that both are seriously impaired in ADHD it is not yet common to include reliable measures of either in treatment protocols. Perhaps the most important additional outcome, particularly when treating with medication is adverse effects. Whilst serious adverse effects with ADHD medications are thankfully uncommon but not unknown there are common adverse effects affecting appetite and sleep and impacts on growth and blood pressure (Graham et al. 2011). Whilst there are clear guidelines for managing these more common adverse effects (Cortese et al. 2013) routine measurement in clinical practice is not common and even when abnormal measures are present they are not always recognised or acted upon. Coghill and Seth (2015) have provided some simple tools for routine measurement in the clinic and these have been recently simplified and updated to include suggestions about monitoring blood pressure (Coghill, 2015, http://bit. ly/1Jme79g).

\section{Conclusions}

There is no one size fits all model of care for ADHD. There are however now strong and clear evidencebased clinical guidelines that can help shape clinical pathways and assist clinicians develop rational and evidence-based clinical pathways. At this time it is probably more important to focus on developing these pathways and adapting them to local circumstances and need than it is for countries without their own clinical guidelines to develop these de novo. The key to optimal ADHD care appears to be careful assessment and monitoring with treatment adjusted in response to the observed outcomes. Unfortunately the evidence would suggest that many clinical services do not yet employ such evidence-based pathways and that as a result optimal clinical care is still some way off for many patients. It would no longer be acceptable to manage other chronic diseases such as diabetes, asthma and hypertension without closely following the key outcome measures $(\mathrm{HbA} 1 \mathrm{C}$, peak flow and blood pressure). Despite the fact that there are no biological markers available to measure outcome in ADHD (similar to hypertension and asthma) the available outcome measures have been demonstrated to be both reliable and valid in real world settings (Adamo et al. 2015) and their use in routine clinical practice appears to improve clinical outcomes significantly (Coghill \& Seth, 2015).

\section{References}

Adamo N, Seth S, Coghill D (2015). Pharmacological treatment of attention-deficit/hyperactivity disorder: assessing outcomes. Expert Review of Clinical Pharmacology 8, 383-397.

Agnew-Blais JC, Polanczyk GV, Danese A, Wertz J, Moffitt TE, Arseneault L (2016). Evaluation of the persistence, remission, and emergence of attention-deficit/hyperactivity disorder in young adulthood. JAMA Psychiatry 73, 713-720. 
Australian Commission on Safety and Quality in Health Care (2015). Attention deficit hyperactivity disorder medicines dispensing 17 years and under. In Australian Atlas of Healthcare Variation, pp. 249-256. Australian Commission on Safety and Quality in Health Care: Sydney.

Banaschewski T, Coghill D, Santosh P, Zuddas A, Asherson P, Buitelaar J, Danckaerts M, Dopfner M, Faraone SV, Rothenberger A, Sergeant J, Steinhausen HC, SonugaBarke EJ, Taylor E (2006). Long-acting medications for the hyperkinetic disorders. A systematic review and European treatment guideline. European Child and Adolescent Psychiatry 15, 476-495.

Banaschewski T, Buitelaar J, Coghill DR, Sergeant JA, Sonuga-Barke E, Zuddas A, Taylor E (2009). The MTA at 8. Journal of the American Academy of Child and Adolescent Psychiatry 48, 1120-1121.

Bolea-Alamanac B, Nutt DJ, Adamou M, Asherson P, Bazire S, Coghill D, Heal D, Muller U, Nash J, Santosh P, Sayal K, Sonuga-Barke E, Young SJ, British Association for P (2014). Evidence-based guidelines for the pharmacological management of attention deficit hyperactivity disorder: update on recommendations from the British Association for Psychopharmacology. Journal of Psychopharmacology 28, 179-203.

Caye A, Rocha TB, Anselmi L, Murray J, Menezes AM, Barros FC, Goncalves H, Wehrmeister F, Jensen CM, Steinhausen HC, Swanson JM, Kieling C, Rohde LA (2016). Attention-deficit/hyperactivity disorder trajectories from childhood to young adulthood: evidence from a Birth Cohort Supporting a Late-Onset Syndrome. JAMA Psychiatry 73, 705-712.

Coghill D (2015). Editorial: painting by numbers: using modern approaches to analyse and visualise clinical and research data. Journal of Child Psychology and Psychiatry 56, 1035-1037.

Coghill D, Hodgkins P (2016). Health-related quality of life of children with attention-deficit/hyperactivity disorder versus children with diabetes and healthy controls. European Child and Adolescent Psychiatry 25, 261-271.

Coghill D, Seth S (2015). Effective management of attentiondeficit/hyperactivity disorder (ADHD) through structured re-assessment: the Dundee ADHD Clinical Care Pathway. Child and Adolescent Psychiatry and Mental Health 9, 52.

Coghill DR, Hayward D, Rhodes SM, Grimmer C, Matthews K (2013). A longitudinal examination of neuropsychological and clinical functioning in boys with attention deficit hyperactivity disorder (ADHD): improvements in executive functioning do not explain clinical improvement. Psychological Medicine, 1-13.

Cortese S, Holtmann M, Banaschewski T, Buitelaar J, Coghill D, Danckaerts M, Dittmann RW, Graham J, Taylor E, Sergeant J, European AGG (2013). Practitioner review: current best practice in the management of adverse events during treatment with ADHD medications in children and adolescents. Journal of Child Psychology and Psychiatry 54, 227-246.

Danckaerts M, Sonuga-Barke EJ, Banaschewski T, Buitelaar J, Dopfner M, Hollis C, Santosh P, Rothenberger A, Sergeant J, Steinhausen HC, Taylor E, Zuddas A, Coghill
D (2010). The quality of life of children with attention deficit/hyperactivity disorder: a systematic review. European Child and Adolescent Psychiatry 19, 83-105.

Faraone SV, Biederman J (2016). Can attention-deficit/ hyperactivity disorder onset occur in adulthood? JAMA Psychiatry 73, 655-656.

Faraone SV, Biederman J, Mick E (2006). The age-dependent decline of attention deficit hyperactivity disorder: a meta-analysis of follow-up studies. Psychological Medicine 36, 159-165.

Geirs DP, Pottegard A, Halldorsson M, Zoega H (2014). A nationwide study of attention-deficit/hyperactivity disorder drug use among adults in Iceland 2003-2012. Basic Clinical Pharmacology and Toxicology.

Goodman DW, Lasser RA, Babcock T, Pucci ML, Solanto MV (2011). Managing ADHD across the lifespan in the primary care setting. Postgraduate Medicine 123, 14-26.

Gordon MK, Baum RA, Gardner W, Kelleher KJ, Langberg JM, Brinkman WB, Epstein JN (2016). Comparison of performance on ADHD quality of care indicators: practitioner self-report versus chart review. Journal of Attention Disorders.

Graham J, Banaschewski T, Buitelaar J, Coghill D, Danckaerts M, Dittmann RW, Dopfner M, Hamilton R, Hollis C, Holtmann M, Hulpke-Wette M, Lecendreux M, Rosenthal E, Rothenberger A, Santosh P, Sergeant J, Simonoff E, Sonuga-Barke E, Wong IC, Zuddas A, Steinhausen HC, Taylor E (2011). European guidelines on managing adverse effects of medication for ADHD. European Child and Adolescent Psychiatry 20, 17-37.

Hinshaw SP, Scheffler RM, Fulton BD, Aase H, Banaschewski T, Cheng W, Mattos P, Holte A, Levy F, Sadeh A, Sergeant JA, Taylor E, Weiss MD (2011). International variation in treatment procedures for ADHD: social context and recent trends. Psychiatric Services 62, 459-464.

Holden SE, Jenkins-Jones S, Poole CD, Morgan CL, Coghill D, Currie CJ (2013). The prevalence and incidence, resource use and financial costs of treating people with attention deficit/hyperactivity disorder (ADHD) in the United Kingdom (1998 to 2010). Child and Adolescent Psychiatry and Mental Health 7, 34.

Huss M, Holling H, Kurth BM, Schlack R (2008). How often are German children and adolescents diagnosed with ADHD? Prevalence based on the judgment of health care professionals: results of the German health and examination survey (KiGGS). European Child and Adolescent Psychiatry 17 (Suppl. 1), 52-58.

Kooij SJ, Bejerot S, Blackwell A, Caci H, Casas-Brugue M, Carpentier PJ, Edvinsson D, Fayyad J, Foeken K, Fitzgerald M, Gaillac V, Ginsberg Y, Henry C, Krause J, Lensing MB, Manor I, Niederhofer H, Nunes-Filipe C, Ohlmeier MD, Oswald P, Pallanti S, Pehlivanidis A, Ramos-Quiroga JA, Rastam M, Ryffel-Rawak D, Stes S, Asherson P (2010). European consensus statement on diagnosis and treatment of adult ADHD: the European Network Adult ADHD. BMC Psychiatry 10, 67.

Langberg JM, Brinkman WB, Lichtenstein PK, Epstein JN (2009). Interventions to promote the evidence-based care of 
children with ADHD in primary-care settings. Expert Review of Neurotherapeutics 9, 477-487.

Langley K, Fowler T, Ford T, Thapar AK, van den Bree M, Harold G, Owen MJ, O'Donovan MC, Thapar A (2010). Adolescent clinical outcomes for young people with attention-deficit hyperactivity disorder. British Journal of Psychiatry 196, 235-240.

Leslie LK, Weckerly J, Plemmons D, Landsverk J, Eastman S (2004). Implementing the American Academy of Pediatrics attention-deficit/hyperactivity disorder diagnostic guidelines in primary care settings. Pediatrics 114, 129-140.

McCarthy S, Asherson P, Coghill D, Hollis C, Murray M, Potts L, Sayal K, de Soysa R, Taylor E, Williams T, Wong IC (2009). Attention-deficit hyperactivity disorder: treatment discontinuation in adolescents and young adults. British Journal of Psychiatry 194, 273-277.

Moffitt TE, Houts R, Asherson P, Belsky DW, Corcoran DL, Hammerle M, Harrington H, Hogan S, Meier MH, Polanczyk GV, Poulton R, Ramrakha S, Sugden K, Williams B, Rohde LA, Caspi A (2015). Is adult ADHD a childhood-onset neurodevelopmental disorder? Evidence from a Four-Decade Longitudinal Cohort Study. American Journal of Psychiatry 172, 967-977.

Molina BS, Hinshaw SP, Swanson JM, Arnold LE, Vitiello B, Jensen PS, Epstein JN, Hoza B, Hechtman L, Abikoff HB, Elliott GR, Greenhill LL, Newcorn JH, Wells KC, Wigal T, Gibbons RD, Hur K, Houck PR (2009). The MTA at 8 years: prospective follow-up of children treated for combined-type ADHD in a multisite study. Journal of the American Academy of Child and Adolescent Psychiatry 48, 484-500.

MTA Group (1999). A 14-month randomized clinical trial of treatment strategies for attention-deficit/hyperactivity disorder. The MTA Cooperative Group. Multimodal treatment study of children with ADHD. Archives of General Psychiatry 56, 1073-1086.

NICE (2008). Attention Deficit Hyperactivity Disorder Diagnosis and Management of ADHD in Children, Young People and Adults. National Institute for Health and Clinical Excellence: London, UK.

Polanczyk G, de Lima MS, Horta BL, Biederman J, Rohde LA (2007). The worldwide prevalence of ADHD: a systematic review and metaregression analysis. American Journal of Psychiatry 164, 942-948.

Rowlingson B, Lawson E, Taylor B, Diggle PJ (2013). Mapping English GP prescribing data: a tool for monitoring health-service inequalities. British Medical Journal Open 3.

Scotland NQI (2008). ADHD Services Over Scotland: Report of the Implementation Review Exercise April 2008. NHS Scotland: Edinburgh.

Setyawan J, Fridman M, Hodgkins P, Quintero J, Haim Erder M, Katic B, Harpin V (2013). Physician-reported treatment outcomes for ADHD among children and adolescents in Europe. Neuropsychiatry 3, 587-600.
Sonuga-Barke EJ, Brandeis D, Cortese S, Daley D, Ferrin M, Holtmann M, Stevenson J, Danckaerts M, van der Oord S, Dopfner M, Dittmann RW, Simonoff E, Zuddas A, Banaschewski T, Buitelaar J, Coghill D, Hollis C, Konofal E, Lecendreux M, Wong IC, Sergeant J, European AGG (2013). Nonpharmacological interventions for ADHD: systematic review and meta-analyses of randomized controlled trials of dietary and psychological treatments. American Journal of Psychiatry 170, 275-289.

Stockl KM, Hughes TE, Jarrar MA, Secnik K, Perwien AR (2003). Physician perceptions of the use of medications for attention deficit hyperactivity disorder. Journal of Managed Care Pharmacy 9, 416-423.

Subcommittee on Attention-Deficit/Hyperactivity Disorder, Steering Committee on Quality Improvement and Management, Wolraich M, Brown L, Brown RT, DuPaul G, Earls M, Feldman HM, Ganiats TG, Kaplanek B, Meyer B, Perrin J, Pierce K, Reiff M, Stein MT, Visser S (2011). ADHD: clinical practice guideline for the diagnosis, evaluation, and treatment of attention-deficit/hyperactivity disorder in children and adolescents. Pediatrics 128, 1007-1022.

Taylor E, Dopfner M, Sergeant J, Asherson P, Banaschewski T, Buitelaar J, Coghill D, Danckaerts M, Rothenberger A, Sonuga-Barke E, Steinhausen HC, Zuddas A (2004). European clinical guidelines for hyperkinetic disorder first upgrade. European Child and Adolescent Psychiatry 13 (Suppl. 1), I7-30.

Turgay A, Goodman DW, Asherson P, Lasser RA, Babcock TF, Pucci ML, Barkley R (2012). Lifespan persistence of ADHD: the life transition model and its application. Journal of Clinical Psychiatry 73, 192-201.

Visser SN, Blumberg SJ, Danielson ML, Bitsko RH, Kogan MD (2013). State-based and demographic variation in parent-reported medication rates for attention-deficit/ hyperactivity disorder, 2007-2008. Preventing Chronic Disease 10, E09.

Visser SN, Danielson ML, Bitsko RH, Holbrook JR, Kogan MD, Ghandour RM, Perou R, Blumberg SJ (2014). Trends in the parent-report of health care provider-diagnosed and medicated attention-deficit/hyperactivity disorder: United States, 2003-2011. Journal of the American Academy of Child and Adolescent Psychiatry 53, 34-46.e2.

Wright N, Moldavsky M, Schneider J, Chakrabarti I, Coates J, Daley D, Kochhar P, Mills J, Sorour W, Sayal K (2015). Practitioner Review: pathways to care for ADHD - a systematic review of barriers and facilitators. Journal of Child Psychology and Psychiatry 56, 598-617.

Young S, Adamou M, Asherson P, Coghill D, Colley B, Gudjonsson G, Hollis C, McCarthy J, Muller U, Paul M, Pitts M, Arif M (2016). Recommendations for the transition of patients with ADHD from child to adult healthcare services: a consensus statement from the UK adult ADHD network. BMC Psychiatry 16, 301. 